PALAVRAS. Revista de Epistemología, Metodología y Ética del Psicoanálisis

ISSN: 2468-9831

www.revistas.unlp.edu.ar/palavras

palavras@outlook.com.ar

Argentina

\title{
PRIMEROS ENCUENTROS ENTRE FEMINISMO Y PSICOANÁLISIS EN ARGENTINA: ENTREVISTA A IRENE MELER
}

DOI $10.24215 / 24689831 \mathrm{e} 026$

Mariela González Oddera

\section{Cómo citar este artículo:}

González Oddera, M. (2018). Primeros encuentros entre feminismo y psicoanálisis en Argentina: entrevista a Irene Meler. Palauras. Revista de Epistemología, Metodología y Ética del Psicoanálisis, 4, 78-93. Recuperado de www.revistas.unlp.edu.ar/palavras 


\section{PRIMEROS ENCUENTROS ENTRE FEMINISMO Y PSICOANÁLISIS EN ARGENTINA: ENTREVISTA A IRENE MELER}

\section{Mariela González Oddera*}

Irene Meler es Doctora en Psicologia y psicoanalista. Cofundadora y coordinadora del Foro de Psicoanálisis y Género de la Asociación de Psicólogos de Buenos Aires, dirige el Curso de Actualización en Psicoanálisis y Género de la Asociación de Psicólogos de Buenos Aires/Universidad Argentina John F. Kennedy. En conjunto con Mabel Burin, dirige la Maestria en Estudios de Género de la Universidad de Ciencias Empresariales y Sociales (UCES). Ha sido docente invitada en diversas universidades y centros académicos de Argentina, México, Uruguay, Chile y Costa Rica. Es autora de numerosas publicaciones realizadas desde el enfoque psicoanalítico de género.

IM: Irene Meler

E: Entrevistadora

\section{E: ¿Qué me podés contar del CEM (Centro de Estudios de la Mujer)?}

IM: En el año 1979, dos grupos de psicólogas, que venían trabajando en Buenos Aires temas relacionados con la condición femenina y el feminismo y leyendo alguna bibliografía al respecto, convocaron en conjunto un seminario, que se llamó La condición de la mujer en la sociedad actual. Fue una jornada de presentación de trabajos, que se realizó en el Instituto Goethe.

\section{E: ¿Estos grupos eran grupos académicos?}

IM: Eran como pequeños grupos de estudio privados. Uno de estos grupos era dirigido por Gloria Bonder y el otro por Mabel Burin. También participó en esas jornadas Ana María Fernández; no sé si convocó a gente que trabajaba previamente con ella. Personalmente, no tenía idea de qué se trataba, pero me invitaron a participar. El tema me interesó mucho y debido a la participación que tuve en las jornadas - yo ya era una psicóloga que tenía 13 años de profesión, con cierta trayectoria y reconocimiento público-, me invitaron a formar parte del CEM, una institución que se fundó en el año 80. Cuando lo estaban fundando, me invitaron a formar parte de la institución.

\footnotetext{
* Facultad de Psicología de la Universidad Nacional de La Plata, Argentina. E-mail: goddera@psico.unlp.edu
} 


\section{E: ¿Los temas en los que trabajabas tenian alguna conexión?}

IM: En esa época hacía clínica con niños, por sobre todo, y no tenía formación previa en género. Tomé contacto con esos desarrollos en aquella ocasión y me resultó muy interesante. Gloria Bonder aportaba una bibliografia extranjera que acá no era conocida, y que permitía aperturas que me convocaron muy intensamente. El CEM básicamente implicó un trabajo de formación auto-gestionada. Gloria coordinó un seminario de formación que consistió en una revisión crítica de los trabajos freudianos sobre la sexualidad femenina y la feminidad. Esa fue la tarea que a mí más me interesó en función de mi práctica clínica y de mi formación de grado, ya que construimos en conjunto una lectura crítica del psicoanálisis. Esa revisión me interesó, estimuló mi propio pensamiento, y por eso al tiempo, alrededor del año 83, empecé a dar cursos en la Asociación de Psicólogos de Buenos Aires, donde planteaba una revisión crítica del discurso freudiano y analizaba la obra de autoras inspiradas en el feminismo.

\section{E: Vos decís que era auto-gestionado; ¿no tenian relación con instituciones oficiales?}

IM: Para nada. Era una ONG, de mujeres, sólo de mujeres. Eso funcionó muy bien en aquella época. Tal vez hoy resulta un poco extraño, sobre todo porque la atmósfera intelectual que se creó no se asemejó en absoluto al el clima separatista de algunas otras instituciones de mujeres, que han sido instituciones lésbicas. En general, éramos todas mujeres heterosexuales, que con mejor o peor suerte, habíamos formado familias. Sin embargo, nos vino muy bien integrar una institución de mujeres. Por ejemplo, yo estudié en una carrera muy feminizada, pero los muy escasos hombres que habia, eran quienes hablaban en clase, los que pedian la palabra, los que ocupaban los paneles en los congresos. Tenian una presencia mucho mayor, que seguramente fue producto de la acumulación histórica de poder, y de asertividad personal. A nosotras nos había costado estudiar con autonomía de criterio. En mi caso fui una estudiante muy buena, pero estudiaba de una manera escolar, para complacer y obtener buenas calificaciones. No había logrado desarrollar en ese entonces, ese espíritu de indagación, de crítica, que adquirí más tarde. Los varones lo tenían desde antes; y si no era así, creían tenerlo. Hablaban con mayor libertad, desarrollaron antes su juicio crítico. Supongo que su autoestima, su fe en sí mismos, eran comparativamente mayores con respecto de las jóvenes de esa época. En consecuencia, el estudio entre mujeres fue muy útil porque permitió que en ese pequeño grupo pudiéramos reflexionar, descubriéramos el placer del estudio, del aprendizaje y del pensamiento crítico. El contexto de estímulo y contención que creamos entre todas, habilitó que desarrolláramos ideas 
propias y confiáramos lo suficiente en nosotras mismas como para escribir y publicar. Y todo eso fue muy positivo para nuestro sector de mujeres, una generación donde muchas de nosotras habíamos sido las primeras profesionales universitarias en nuestras familias. Fuimos la primera generación que tuvo trabajos remunerados, que nos permitieron una autonomía económica para la cual no había modelos, ya que la mayoría de nosotras éramos hijas de madres domésticas. Ese fue un cambio histórico muy grande que quizá es dificil de captar para las generaciones más jóvenes, que atraviesan por circunstancias distintas, aunque enfrentan sus propios problemas.

E: ¿Y esa novedad del rol social que tenian aparece en los escritos, no? Leyendo la compilación de Mabel Burin hay un intento de reflexionar muy en primera persona: la propia situación social, los mandatos que atravesaron la propia experiencia.

IM: Eso es variable. Mi trabajo tiene un enfoque más académico, mientras hay otros que son más testimoniales. Yo te diría que me ajusté de entrada a una estrategia de producción teórica más clásicamente masculina, seguramente porque me parecía más respetable. Mientras que otras compañeras prefirieron un abordaje más testimonial, de la experiencia.

\section{E: No solamente a lo testimonial me queria referir, sino a la implicación del autor en la producción.}

IM: Bueno, ese es uno de los supuestos epistemológicos que ya se manejaban en el CEM, en el sentido de que si nosotras estudiábamos la condición femenina a partir de nuestra experiencia, éramos a la vez objetos y sujetos de la investigación. En ese sentido, esto era planteado como una particularidad epistemológica de este campo.

\section{E: Como un aporte también de la epistemologia feminista.}

IM: Que estábamos empezando a conocer, en ese momento.

\section{E: ¿Y qué autores leían?}

IM: Leímos muchísimos autores extranjeros, de distintas disciplinas. Después del período inicial se fundó la Carrera de Estudios de la Mujer, en la Facultad de Psicología de la UBA. Básicamente los programas y la bibliografia fueron obra de Gloria Bonder, con el aporte de Ana María Fernández. Veíamos textos de Bourdieu, de Foucault, de Bruner; esos autores fueron aportados por Ana María. Muchas autoras feministas norteamericanas y francesas, Christine Delphy, Kate Millett, Shulamit 
Firestone, Jean Bethke Elshtein, muchísima bibliografia que era muy novedosa. Leímos a Gayle Rubin, y a Kate Millett, por supuesto. Lo que te puedo decir es que era mucho [risas] y que tuvimos que aprender a leer en inglés, francés, portugués, porque por supuesto no había traducciones disponibles. La Carrera Estudios de la Mujer se creó en el 87; primero se dieron unos cursos breves, en los que participé la segunda vez que se dictaron. Los primeros se dieron en el 85 y en el 86 me invitaron a participar. Cuando se abrió la carrera en el 87 ya pasé a ser docente de la carrera. Y terminé haciéndome prácticamente cargo de esa carrera, no oficialmente, pero sí en la práctica, porque Gloria había fundado el Programa Nacional de Igualdad de Oportunidades para la Mujer en el Área Educativa, $(P R I O M)$, en el Ministerio de Educación de Nación. Pese a que el Sub Programa Universidades, que funcionó como parte del PRIOM, estaba a mi cargo, tuve más disponibilidad y, en la práctica, en función de haber logrado un crecimiento, un gran aprendizaje, estuve en condiciones de coordinarla de hecho. Era una carrera que tenía una estructura en la que se inspiró más adelante la Maestría en Estudios de Género que armé en conjunto con Mabel Burin, en la UCES. Trabajábamos en asignaturas que tomaron como objeto mujer y familia, mujer y trabajo, mujer y educación, mujer y salud, políticas públicas destinadas a las mujeres, en fin, había materias que abordaron de modo interdisciplinario, distintas áreas de la experiencia social.

En el CEM el trabajo consistió sobre todo grupos de estudio gestionados de modo colectivo, y en grupos de reflexión, donde invitábamos a otras mujeres. Por ejemplo Clara Coria, que lideró esa iniciativa, hizo grupos sobre dinero, que después dieron lugar a su primer libro.

\section{E: Estos eran los grupos abiertos a la comunidad}

IM: Sí, se organizaban por redes de conocimiento personal. Era una comunidad más acotada. Personalmente, coordiné grupos sobre divorcio y sobre mujeres solas, también viudas...Hoy puedo situar allí el origen de mi tesis doctoral sobre familias ensambladas, que dio origen al libro Recomenzar. Estela Rodríguez Giles y Yudith Graschinsky coordinaron en La Plata grupos sobre el tema de La mujer y el poder.

\section{E: ¿Y este dispositivo de grupos de reflexión?}

IM: Fue muy útil y muy productivo. A las mujeres les gustaba mucho poder participar y reflexionar sobre su experiencia. La idea era que no se confundiera nunca con un grupo terapéutico, es decir que los aportes vivenciales de las participantes permitieran una generalización, no una particularización, para pensar el modo en que las vivencias específicas de cada una de las integrantes se inscribian en una condición social que compartíamos en común. Y eso fue muy productivo, tanto para las mujeres 
que formaron parte de los grupos, como para nosotras, que los coordinamos, y produjo muchísimo aprendizaje.

\section{E: ¿Cómo se desarrollaban? ¿Qué duración tenian?}

IM: Era una duración acotada.... Creo recordar que funcionaron con una frecuencia semanal, había un período pactado de aproximadamente cuatro meses, y si el grupo lo deseaba, se acordaba funcionar durante otro período similar. Mi experiencia en los grupos de mujeres divorciadas fue positiva, más adelante hice otro grupo con mujeres solas, incluyendo a solteras y viudas.

\section{E: Sin pareja}

IM: Claro, en ese momento las llamábamos solas. Hoy día las llamariamos sin pareja. También implementamos programas sociales. Gloria Bonder había logrado gestionar subsidios para sostener esos programas. Ella dirigió un programa sobre educación sexual en la adolescencia; yo dirigi un programa destinado a la educación sexual de mujeres adultas. Cristina Zurutuza estudió la situación de las trabajadoras domésticas.

\section{E: ¿Lo presentaron acá, en la ciudad de Bs As?}

IM: No, no, nada gubernamental. Se presentaba un proyecto ante fundaciones u ONGs internacionales. Para el programa que yo dirigí, el subsidio provino del Consejo Inter Eclesiástico Holandés (ICCO); era un subsidio muy pequeño que nos permitía cubrir los traslados y nos proporcionaba un bajo ingreso mensual. Lo dirigi contando con tres colaboradoras en la primera fase, y dos en un segundo período. Fueron una médica, Alicia Ferreira, y dos psicólogas: Norma Ruiz y Olga Rosemberg. Trabajamos en la periferia de la ciudad de Campana, con grupos de mujeres que convocábamos en los barrios. Armábamos una planificación sobre la base de una experiencia piloto. Utilizamos la metodología de talleres planificados para trabajar distintos temas. Básicamente el eje de los talleres consistió en lograr una autonomía mayor por parte de las mujeres: que regularan su fecundidad para mejorar su situación, tanto dentro de la pareja como en la sociedad, y acceder a trabajos remunerados. Porque la multiparidad precoz y poco espaciada, prácticamente las condenaba a la domesticidad y a la dependencia con respecto de los compañeros, lo que las hacía vulnerables a la violencia. Entonces la idea era lograr que sociabilizaran entre ellas, que se empoderaran, que construyeran mayor autonomía. Fue una experiencia muy linda y sorprendente, por momentos. Por ejemplo, recuerdo que una mujer dijo... "Claro, yo no entiendo tal cosa, porque no tengo canillas". Nosotras éramos señoras que veníamos de Barrio 
Norte en auto y nos encontrábamos con que ellas tenían bomba de agua, no tenían canillas. Yo había hecho un convenio con la Asociación de Protección Familiar para que les proveyera anticonceptivos y ellas viajaban con el apoyo de la Municipalidad con la que había firmado un convenio para que les costearan los pasajes. Viajaban a la capital y recibian charlas y provisión de anticonceptivos de la Asociación Argentina de Protección Familiar (APF). Un día me contaron: "¿Sabe que yendo a la asociación, la Dominga conoció el subte?"

\section{E: La experiencia urbana}

IM: Claro... para mí fue como un choque cultural, supongo que para ellas también. El barrio en el que trabajé estaba al lado de un country; las mujeres trabajaban de mucamas y los hombres, de jardineros. Y entonces, refiriéndose a otro de los barrios, la funcionaria municipal con la que traté me dijo: "Mirá que en el barrio en el que vos vas a trabajar, los hombres están todos presos". Como que con las mujeres se podía hablar, pero los hombres eran todos delincuentes. Claro, la transgresión era endémica en una población excluida. Y fui aprendiendo de la experiencia, ya que no tenía muy claras las cosas cuando empecé. Fui comprendiendo la situación de ese sector social de mujeres a medida que iba trabajando y mi propósito implícito consistió en ese momento en compartir la estrategia de ascenso de los sectores medios: reducir la natalidad e incorporar a las mujeres al mercado de trabajo. En ese período no logré cuestionar el sistema, simplemente traté de incorporar a las mujeres excluidas al proceso de modernización.

\section{E: ¿Y esta era una aspiración que estaba en juego en los barrios, también?}

IM: Había de todo. Había mujeres mucho más autónomas que tenían un solo hijo y levantaban quiniela, una actividad ilegal, porque valoraban disponer de recursos económicos propios. Otras mujeres tenian 7 u 8 hijos pasados los veinte años...no existe una homogeneidad dentro de los sectores populares, como no la hay en ningún sector social. Sólo el prejuicio unifica, falsamente por supuesto. Sobre la base de la experiencia en los talleres, elaboramos materiales de apoyo, materiales de educación popular. Esto fue en los años 90; en paralelo, la Carrera de Estudios de la Mujer estaba funcionando.

En cuanto al clima emocional de la institución, yo te diría que fue virando de una manera casi dramática.

\section{E: ¿Cuántas eran?}


IM: No era un grupo grande, no recuerdo bien, pero no llegábamos a 20.

\section{E: ¿Dónde se reunian?}

IM: Se alquiló una casa en Thames y Nicaragua, gestionada por Mabel Burin. Al principio la sede fue un departamento, y luego se alquiló la casa. Ahí se podian hacer los grupos...una casa antigua, en una esquina.

\section{E: ¿Y las mujeres que participaban eran de clase media, también?}

IM: Sí, totalmente. Te contaba sobre las relaciones internas de la institución; al principio el vínculo entre nosotras fue muy grato. Había un clima de solidaridad, de apoyo mutuo, de pertenencia y de agradecimiento recíproco por estar aprendiendo cosas tan interesantes y por estar creciendo... ¡la verdad es que fue tan bueno para muchas de nosotras! Nos permitió un desarrollo que no sé si hubiéramos logrado de otra manera. Porque era muy duro ejercer la profesión en ambientes muy hegemonizados por los hombres, que eran una minoría desde la perspectiva estadística, pero funcionaban de modo mayoritario en los ámbitos académicos.

Fue una experiencia liberadora, no sólo teóricamente, sino por la experiencia práctica de autonomía y de crecimiento intelectual y profesional. Yo venía, anteriormente a mi inclusión en la institución, con un desarrollo propio, porque entre otras inserciones laborales, intervenía en los medios de comunicación. En el Hospital de Niños había estado trabajando medios de comunicación con Eva Giberti, estaba escribiendo en revistas destinadas a mujeres, como Para Ti, artículos de divulgación psicológica, había participado en programas de televisión, de modo que tenía visibilidad como una profesional con un perfil alto y personal. Pero la pertenencia a ese grupo fue muy importante como formación y como crecimiento profesional, para muchas de nosotras. Y después de a poco empezaron los resentimientos y las rivalidades. En un período inicial percibimos lo que nos igualaba, porque compartíamos la condición de estar socialmente subordinadas, y habiamos tomado conciencia de ello, lo que generó un clima que hoy se denomina como "sororidad". Más adelante, empezaron a aparecer las rivalidades. Se comenzó a notar, en un clima de conflicto y sufrimiento vincular, quién era mejor profesional, quién tenía más limitaciones, quién era más capaz o más creativa...y esto fue generando los primeros cismas. Mabel Burin, por ejemplo, no llegó a la fundación de la carrera; ella contribuyó a fundar el CEM, pero cuando se fundó la Carrera de Estudios de la Mujer ya se había retirado de la institución. Clara Coria también se retiró antes; ella después se manejó sola. Escribe muy bien, con facilidad, y se desarrolló de modo individual, nunca más formó parte de un agrupamiento feminista de otra especie. Y no hizo una carrera académica, aunque fue invitada por muchas universidades. Personalmente, fui de las personas que continuó en la 
institución por más tiempo, pero con mucho malestar, por percibir manejos de poder que me resultaban muy desagradables. Estaba muy incómoda, en desacuerdo con muchas de las actitudes, hasta de las políticas que se tomaban. De modo que fui buscando otra forma de seguir con lo que me interesaba y que ya había incorporado a mi identidad laboral. En ese período de conflicto, un día Debora Tajer, que era ya una persona joven muy proactiva, me planteó: "Meler, yo no sé Psicoanálisis, pero me gustaría aprender. ¿Por qué no fundamos un Foro de Psicoanálisis y Género?” Era justo lo que necesitaba, ya que era una persona que aunque muy estudiosa, tenía mayores inhibiciones, era comparativamente de mayor edad, con más trayectoria, pero menos arriesgada y audaz. Fundamos el Foro y convocamos a un Comité Asesor, donde incluimos a Ana María Fernández, a Juan Carlos Volnovich, a Norberto Inda, que posteriormente se desvinculó porque se planteó una divergencia conceptual, a Eva Giberti y a Mabel Burin. Fue la manera que encontré de continuar mi desarrollo, fundando un espacio dedicado a los temas que venía trabajando, pero independizándome de ese primitivo grupo. Esas cosas que pasan en las instituciones, que entre las personas, lamentablemente, surgen rivalidades, hostilidades, es parte del destino de los grupos humanos.

\section{E: E1 CEM se fue desmembrando}

IM: Sí. Y con el paso de los años, quedó reducido a un sello. $Y$ en este momento, que yo sepa, no funciona. Yo me retiré en el 95, al fundarse el Foro. Hasta ahí, existía, pero ya mucho más reducido. Primero se desvinculó Clara Coria, después Mabel Burin, finalmente me retiré yo. Éramos de las personas que más desarrollo intelectual habíamos logrado en ese contexto. Se fue empobreciendo... no hubo un reemplazo generacional suficiente, como para que Gloria pudiera mantenerlo con otras colegas.

\section{E: La figura de Gloria era bastante central, ¿no? De lo que pude leer de los libros, es una referencia obligada de casi todos los capítulos.}

IM: Es mucho menos citada de lo que se mereceria, por sus dificultades vinculares. Porque ella realmente ha tenido el mérito de abrir este campo en el país y nos ha permitido a muchas de nosotras, acceder a bibliografia y a pensamientos que después nos han habilitado para un desarrollo personal. Y ha sido poco citada por esta mala relación que ha tenido con las personas.

Bueno, esto es lo que recuerdo del CEM: que fue una institución pionera, que agrupaba sobre todo a psicólogas. Hubo otros agrupamientos que reunian a historiadoras, que fueron incluso un poquito anteriores.

\section{E: ¿Y por qué psicólogas?}


IM: No lo sé. Gloria Bonder era psicóloga, Ana María Fernández, Clara Coria, Mabel Burin, Eva Giberti, Cristina Zurutuza, Susana Velázquez, Esther Moncarz, yo...Pese a eso, el enfoque fue interdisciplinario.

\section{E: ¿Y todas hacian clínica?}

IM: Sí, de las colegas que te nombré, todas hacian clínica. Algunas otras que llegaron después, por ahí no, pero las primeras tuvimos una práctica como psicoterapeutas.

\section{E: ¿Y no se planteó en algún momento incluir mujeres de otras profesiones?}

IM: Bueno, la Carrera de Estudios de la Mujer fue interdisciplinaria y en el cuerpo docente había muchísimas mujeres de otras profesiones: sociólogas, historiadoras, antropólogas, incluso una bióloga. A medida que la carrera y el programa se fueron desarrollando, la energía se fue orientando hacia esas actividades y cada vez menos hacia el interior de la institución. Cuando Gloria presentó el Programa Nacional de Igualdad de Oportunidades en el Ministerio de Educación, convocó a Graciela Morgade, que fue su colaboradora principal, porque trabajaba en el campo educativo. Su interés se enfocó en educación y en las políticas públicas. Eso fue también un motivo de alejamiento, porque ya existía una diferencia de intereses. A mí me interesaba la subjetividad, la clínica y a ella le interesaban las politicas públicas.

\section{E: ¿Qué relación tenía con otras instituciones? De psicólogos, de psicoanálisis...}

IM: De a poco, fuimos presentando trabajos en congresos; no había una articulación de institución a institución. Nos fue ocurriendo, más que como producto de una estrategia deliberada, nos fue ocurriendo que a medida que íbamos pensando, íbamos dando cursos, íbamos presentándonos en congresos... De ser una especie de extrañas, marginales e ignotas, pasamos a lo largo de los años a ser cada vez más reconocidas y a ir formando una corriente de opinión. Con la fundación del Foro de Psicoanálisis y Género, eso se fortaleció mucho, al ser una articulación específica dentro de un campo interdisciplinario más amplio. En una ciudad con un notable desarrollo psicoanalítico, al articular una teoría que era hegemónica, como el psicoanálisis, con los estudios de género, se fue dando mayor interlocución con otras instituciones. Fuimos pasando de ser ignoradas a tener mayor reconocimiento.

\section{E: Las veian como algo sectario}


IM: El feminismo en los ámbitos psicoanalíticos, fue inicialmente decodificado como una especie de reacción neurótica a un trauma personal. Y de ser así, una especie de parias exóticas, nos fue ocurriendo, por avatares de la historia social y de nuestras biografias inscriptas en ella, que en la medida en que fuimos publicando obtuvimos mayor reconocimiento. Cuando en 2015 invité a la Argentina a Michel Tort, y fue posible traerlo con el concurso de muchas instituciones locales que trabajan en el campo psicoanalítico, tales como APA, FEPAL, la Asociación de Grupos, ASAPPIA, El Colegio de Psicoanalistas y la publicación virtual El Psicoanalítico, se obtuvo un logro relevante.

\section{E: Es notable cómo los estudios de género han pasado de esa marginalidad inicial a tener una cierta centralidad. Los psicoanalistas, aunque no lo compartan, al menos les hacen un lugar.}

IM: Nos respetan, por ahí no nos comprenden del todo, aunque algunos sí lo hacen. Michel Tort, por ejemplo. Él vino porque una de las colegas que cursan un seminario que coordino de forma privada", me dijo: “¿Por qué no lo invitas a las jornadas del Foro?, porque él te leyó y posiblemente aceptaría. Tengo una amiga en común, que le llevó cosas de acá y te leyó”. ¡A mí me llevó como un mes reponerme de la emoción que me produjo que un psicoanalista cuya obra admiro y que se desempeña en un país central, me hubiera leído! Lo invité y me respondió a vuelta de correo, aceptando el intercambio. O sea que hay autores con los que coincidimos mucho -por ejemplo, Nancy Chodorow o Jessica Benjamin, de EEUU-, y que nos han inspirado. Jessica Benjamin, una destacada psicoanalista con perspectiva feminista, que reside en Nueva York, estuvo en Buenos Aires y dio una conferencia en unas Jornadas convocadas por el Foro de Psicoanálisis y Género. Incluso hemos publicado algunas ideas en forma previa a las publicaciones provenientes del exterior, aunque por nuestra ubicación periférica no tuvieron difusión. Son ideas que están en el espíritu de la época. O sea que no es que acá seamos un eco de lo que se produce en las metrópolis, sino que tenemos una producción personal que está a la altura de lo que se piensa en el mundo. Y esas son cosas que me han sorprendido muchísimo, de modo favorable.

Pilar Errázuriz ${ }^{2}$ es una psicoanalista chilena que vivió varios años en Francia y gracias a su excelente dominio del francés, tradujo varios trabajos nuestros que ella eligió, producciones de Mabel Burin, parte de un artículo mío, trabajos de Ana Fernández y de Débora Tajer, realizó una compilación, incluyendo también un trabajo de su autoría y la tituló Au sud du Sud. Tal

\footnotetext{
${ }^{1}$ Lic. Liliana Niemtzoff

${ }^{2}$ Pilar Errázuriz formó parte del Comité Asesor del Foro de Psicoanálisis y Género. Lamentablemente falleció de modo prematuro.
} 
vez el año que viene salga publicada en París. Son procesos muy sorprendentes. Esta es una cuestión generacional: la gente más joven tiene una idea de desarrollo de carrera. Pero nosotras fuimos en términos generales, la primera generación de universitarias, la primera generación de mujeres que nos ganábamos la vida al menos en nuestro entorno familiar y social. El desarrollo de carrera que hicimos no respondió a una clara idea de progreso personal, más bien fue como quien no quiere la cosa. No fue el caso de Debora Tajer o de Irene Fridman, que se incorporó más tarde al Foro de Psicoanálisis y Género como Secretaria de Difusión y codirigió conmigo el Curso de Actualización en Psicoanálisis y Género hasta 2013. Las colegas más jóvenes pudieron desplegar sus proyectos con menores inhibiciones.

\section{E: ¿Y cómo fue esto del Foro?}

IM: Para armar el Foro me inspiré un poco en la experiencia que tuve colaborando con Eva Giberti en la Escuela para Padres de la Facultad de Medicina, en mi temprana juventud. Eva convocaba encuentros abiertos al público en el Hospital Gutiérrez, relacionados con la niñez, la crianza, las relaciones familiares, etc. La idea de hacer paneles abiertos al público, la tomé de ella. Yo me formé con ella en ese aspecto, en su momento fui una de las primeras hijas de Eva. Así que empecé con esta actividad, tomando temas de interés actual sobre los que exponian expertos de alguna disciplina, siempre incluyendo un profesional del campo del psicoanálisis o de la psicología y en ocasiones, creando un panel con la participación de investigadores provenientes de otras disciplinas sociales o humanas. Y el Foro, fundado en 1995, ya cumplió 24 años.

\section{E: ¿Y dónde funcionaba?}

IM: Comenzó funcionando en el la Fundación del Banco Patricios, un espacio que consiguió Eva Giberti. Y luego, también por iniciativa de Débora Tajer, empezamos a convocar las Jornadas, que empezaron siendo anuales y ahora son bianuales. Más adelante creamos, en conjunto con Mabel Burin, la Maestría en Estudios de Género que funciona en la Universidad de Ciencias Empresariales y Sociales. Son espacios que se sostienen y habilitan una formación interdisciplinaria sistemática en Estudios de Género, en el caso de la Maestría, y en la articulación entre psicoanálisis y género en el caso del Curso de Actualización en Psicoanálisis y Género que dirijo en la Asociación de Psicólogos de Buenos, Aires avalado por la Universidad Argentina John F. Kennedy. Ese Curso se dicta hace 22 años, y es ya un espacio clásico de formación de profesionales en este enfoque.

\section{E: ¿En el CEM eran todas psicoanalistas?}


IM: Mayormente sí. Ana María Fernández decía en un momento que ella no hacía psicoanálisis sino psicología social, pero después retornó al campo psicoanalítico. Yo siempre me consideré psicoanalista, aunque nadie me avaló, porque no hice los seminarios, pero los psicoanalistas me reconocen, porque me invitan a APA, a APdeBA; reconocen que tienen una interlocución que les interesa. Soy como una psicoanalista rebelde... toda familia tiene alguna.

\section{E: ¿Y vos hiciste una residencia?}

IM: Sí, soy egresada de la primera residencia para psicólogos que hubo en el Hospital de Niños; se llamaba "Residencia en Psicología Clínica Infantil". Me recibí de Licenciada en Psicología en 1967; de modo que habré egresado de la Residencia en el año 69. Era una residencia de medio turno; no fue full time como el régimen formativo de los médicos. Tampoco tuvimos remuneración, y el reconocimiento de la Facultad de Medicina fue posterior al inicio de nuestra práctica. Lo hacíamos con una dedicación absoluta. Ya se han cumplido cincuenta años del comienzo de esa Residencia.

E: Cambiamos un poco de tema... Yo estoy investigando los origenes de la violencia familiar como problema en la psicologia argentina. Voy trabajando distintos núcleos sobre los que se ha tematizado la cuestión de la violencia y la familia y me he encontrado con publicaciones del CEM que se han ocupado del tema, aunque en forma más tangencial. Así que te pregunto: ¿han trabajado especificamente el tema violencia? ¿Cómo lo han hecho?

IM: Sí. En el CEM la psicóloga que trabajó sobre el tema de la violencia fue Susana Velázquez; pero no lo hizo en la época en que pertenecía al CEM, sino más tarde. No sé exactamente en qué año publicó su primer libro; pero no recuerdo que trabajara sobre la violencia cuando estaba en el CEM.

\section{E: Seguramente fue a partir de la década del 90}

IM: Seguramente será como vos decís, yo no he estado tan cerca de ella en el CEM, cada una hizo su desarrollo en forma independiente. Los libros de Susana, a quien hemos perdido de forma prematura, son relativamente recientes y conozco que ella tenía, lógicamente, una experiencia previa a sus publicaciones. Pero no se remonta a los años 80; debe haber sido a partir de los 90 .

E: Yo estuve trabajando con algunas publicaciones que incluyen autores del CEM, como el libro de Mabel Burin, Estudios sobre la subjetividad 


\section{femenina. Alli hay autores que trabajan en forma más colateral el tema de la violencia.}

IM: Un libro compilado por Eva Giberti y Ana María Fernández, se tituló La mujer y la violencia invisible; las autoras tomaron el tema de la violencia, pero no del modo en que después se lo abordó en Argentina, donde el foco se puso sobre violencia física, sino que se enfocaron en la violencia simbólica. Más adelante se ha tipificado la violencia económica, la violencia psicológica... en fin, las distintas subespecies de violencia, pero el foco inicial se puso sobre los ataques físicos de los varones contra las mujeres. ¿Ese libro en qué año se publicó?

\section{E: Del 89, la primera edición.}

IM: Para esa obra, las autoras tomaron el concepto bourdiano de violencia invisible. Bourdieu conceptualizó la violencia en su aspecto simbólico, que incluye la participación subjetiva de la víctima. Los enfoques que desimplican por completo con respecto de su situación, a las mujeres que son víctimas de violencia, corren el riesgo de dar una imagen sobre ellas que las priva de subjetividad.

\section{E: Claro... esa es la tematización propia del feminismo; una ampliación de la referencialidad de la violencia}

IM: No sólo es propio del feminismo, que a veces en el afán de deslegitimar los actos violentos, ha omitido el estudio de las subjetividades en juego. E1 enfoque estructural de Rita Segato incluye las representaciones colectivas sobre la masculinidad cultural, y es muy interesante y necesario. Personalmente, me he interesado tanto en los factores contextuales como en los aspectos intersubjetivos del drama de la violencia contra las mujeres.

\section{E: ¿Te acordás en qué momento te encontraste con este tema, con qué teorias?}

IM: Cuando se fundó la Carrera de Estudios de la Mujer, en el 87, creo que al mismo tiempo se fundó la carrera de Especialización en Violencia Familiar, dirigida por Jorge Corsi. En determinado momento se estableció un convenio por el que los estudiantes de esa carrera cursaban alguna materia opcional en la Carrera de Especialización en Estudios de la Mujer. Tomé contacto de ese modo con gente que hoy día es muy reconocida, a quienes convoqué cuando me ha tocado organizar un curso enfocado en la atención de varones violentos, para la Fundación Barceló. Como lo que me es posible aportar, se refiere a los aspectos teóricos, convoqué a Darío Ibarra Casals, un psicólogo y sexólogo que vive en Montevideo y trabaja con varones, a 
Mario Payarola, psicólogo argentino que fundó una red para la asistencia a varones violentos, y hoy trabaja en la Oficina de Violencia Doméstica de la Corte Suprema de Justicia, a Irene Fridman, quien se desempeña como supervisora clínica en la OVD, tanto en la capital como en algunas localidades del interior y también trabaja con el BID, entre otros colegas.

\section{E: ¿Pero en el CEM era un tema extraterritorial? ¿No era un tema sobre el que trabajaban?}

IM: No. Al principio, no. No nos gustaba mucho.

\section{E: ¿Por qué?}

IM: No sé; no te sabría decir. Recuerdo que Gloria Bonder dudaba de que ese fuera un objeto de estudio legitimo.

E: Porque es notable cómo ha quedado por fuera de la reflexión de los estudios de género, en este primer tiempo

IM: Yo me he dado cuenta con el tiempo... Irene Fridman, que trabajó conmigo muchos años, se ha especializado en ese campo. Ella se abrió camino como supervisora de equipos dedicados a la atención de mujeres víctimas de violencia; obtuvo una gran proyección personal por esa tarea. Pero eso no lo aprendió conmigo; lo hizo por su cuenta. Y no... es un tema que nunca me gustó. Más vale he tenido prejuicios al respecto.

E: ¿Habrá tenido que ver con alguna asociación entre violencia y pobreza? Hay un sentido coagulado sobre que no hay violencia en los sectores medios...

IM: Creo que se relaciona más con el hecho de que cuando se está en situación de violencia no es posible pensar; y la urgencia que implica el tema de estudio puede haber promovido en un comienzo que la producción fuera escasa y pobre. He desarrollado algún esfuerzo para teorizar la violencia vincular, para intentar contrarrestar esa tendencia operativa, que con frecuencia naufraga en el pensamiento operatorio. Pero el motivo principal es de indole emocional: reconocer el modo en que la violencia ha afectado nuestra existencia personal, es un proceso doloroso y en cierto sentido, humillante.

E: Sí... es cierto que no hay demasiados trabajos académicos sobre el tema, aún hoy 
IM: Ante la emergencia, uno se pone operativo. Y de lo operativo, se desliza fácilmente a lo operatorio, a tener un pensamiento como el de los estados psicosomáticos, donde el sujeto está disociado, empobrecido, y donde, actúa para enfrentar la emergencia, para sobrevivir o ayudar a que el otro sobreviva.

\section{E: Hay igual algunos focos teóricos. Habria que pensar por qué no se aborda en forma más sistemática}

IM: Y yo creo que si pensás no te ponés violenta, que es por eso... porque es algo que la gente hace cuando no puede pensar. Las mujeres les pegan a los ancianos, porque somos las que más cuidan a los ancianos, y a los niños. Y los hombres nos pegan a las mujeres. Digamos que la violencia es parte de la vida...

Sobre esta temática, yo he tenido poco interés, en parte, porque es un tema que no ha tenido mucho desarrollo teórico, y yo soy básicamente una teórica. Y en parte, por resistencia; hoy en día lo puedo reconocer. Ha sido como una defensa, porque como una vez le escuché decir a Eva Giberti, con toda razón, a nadie le gustan las víctimas. Y a mí tampoco; no me gustaba sentirme lesionada por la violencia que, creo que sí, lo he sido.

\section{E: Volviendo a las lecturas que hacian en el CEM...}

IM: Los textos que tengo más presentes son los que provienen del feminismo psicoanalítico: Luce Irigaray; Nancy Chodorow, Jessica Benjamin. Las psicoanalistas feministas son las que más me interesaron.

\section{E: En las referencias bibliográficas aparece más bien esta articulación. Quizá la lectura del feminismo -por si mismo- ha sido posterior.}

IM: En general he leído sociólogos, psicólogos... no tanto filosofia feminista. No me atrajo tanto. Otras colegas han trabajado más desde la filosofia. Yo no he trabajado tanto en el campo de las teorias feministas; no me he dedicado a eso. Me he dedicado al estudio de la subjetividad desde una perspectiva psicoanalítica informada en el enfoque de género.

E: Como posición teórica, me ha resultado interesante esta revisión critica del psicoanálisis, pero desde adentro del psicoanálisis.

IM: Claro... por ejemplo, en el libro Recomenzar, dediqué un capítulo a la revisión de los conceptos freudianos, y otro capitulo al análisis de algunos aportes contemporáneos. A mí me interesa esa tarea teórica.

\section{E: Es una articulación singular la de género y psicoanálisis}


IM: Y sí.. es una teoría que está atravesada por el sexismo y el androcentrismo, como tantas otras, pero que constituye el origen de mi actividad, de mi inserción en la profesión y en el mundo. De modo que se trata de superar el apego a ciertos conceptos que han quedado obsoletos y aportar en lo que sea posible, a la construcción de nuevas herramientas teóricas y clínicas. 